\title{
Dynamism of Chinese Entrepreneurship in Australia
}

\author{
Christopher Selvarajah \\ Swinburne University \\ E-Mail: cselvarajah@swin.edu.au \\ John Chelliah \\ University of Technology, Sydney \\ E-Mail: john.chelliah@uts.edu.au \\ Henri Lee \\ Swinburne University \\ E-Mail: henri.lee@ hotmail.com
}

\begin{abstract}
This study identifies the key factors that enable Chinese entrepreneurs to set up and operate their business ventures in Australia. Data was collected from 200 Chinese entrepreneurs through a survey questionnaire and was analysed using factor analysis and regression analysis. The findings show that key factors, such as background of entrepreneurs, entrepreneurial motivations, traditional Confucian values, difficulties and hurdles faced, and the vision of expanding overseas contributed to the success of the businesses. This research may be of interest to policy makers, small business consultants and academics because it highlights key success factors relevant to small ethnic Chinese based businesses and the challenges they face.
\end{abstract}

Keywords: Entrepreneurship, Chinese Migrants, Small Business, Confucianism, Australia

\section{INTRODUCTION}

Migrants from all over the world have contributed to Australia's economic growth since its European settlement in the $19^{\text {th }}$ century. The history of ethnic Chinese immigrants who came from Southeast Asian countries and mainland China is well 
researched (for e.g. Ahlstrom et al., 2004; Chan, 2008). However, this has always been in the form of a linear narrative description, and there has been relatively little research on the entrepreneurial behaviours of the first and second generation ethnic Chinese entrepreneurs in Melbourne or other cities. What are the generational differences in regard to entrepreneurial behaviour?

This paper is an exploratory study of Chinese entrepreneurship in Australia, specifically the first and second generation immigrants. This research has three key benefits:

- It provides an understanding of the skills and human resources required for Australia's economic development;

- It provides insight into the needs of migrant entrepreneurs; and

- It can guide federal, state and local government in economic policy planning.

With the progress of time and social adaptation, the working philosophies and styles of the businesses' operations are bound to change as the second generation entrepreneurs take over from the first (Rusinovic, 2008). The organisational complexity is bound to increase in this progression, including the nature of the business, the size of the organisation and the human resource requirements. This evolution is explored in this research.

\section{LITERATURE AND HYPOTHESES DEVELOPMENT}

\section{Background of Entrepreneur}

This study is informed by the literature pertaining to human and financial capital as well as that pertaining to social learning theory (Bandura, 1977), which together provide a complementary perspective to the resources-based view. Theoretical perspectives in the specified areas are used to develop a hypothesis about the background of the Chinese entrepreneurs that includes their education level, prior work experience, entrepreneurial family background and the extent of their finances. 'Guanxi connections', which includes personal networking (Kempster and Cope, 2010) and local know-how (Tsang, 1998; Yang, 2002), is also included in this investigation. The possession of human capital (capabilities, business skills and knowledge derived from education, previous work experience and entrepreneurial family background) and financial capital (access to funds) have been found to differentiate successful entrepreneurs from less successful ones (Brush et al., 2006). Thus it is hypothesised that:

H1. The success of the business is related to the background of the entrepreneurs. 


\section{Motivation}

Generally, the motivation for a business venture is based on personal attributes and a vision of the entrepreneurial pathway. For instance, psychological motivations such as freedom, desire for the potential to make more money, and strong belief in one's own capability have been widely linked to businesses (Lerner et al., 1997).

The second major motivation can be explained by the 'push and pull' theory, which is now a common way of explaining different motivations to start a business (Amit and Muller 1995). Push factors are elements of necessity such as insufficient family income, dissatisfaction with a salaried job, unemployment, and a need for a flexible work schedule because of family responsibilities. Pull factors relate to personal desires for independence, self-fulfilment, entrepreneurial drives, and desire for wealth and social status (Amit and Muller 1995).

It is therefore likely that the motivational factors of Chinese entrepreneurs influence their business success, so:

H2. Entrepreneurial success is related to the motivation of the entrepreneurs.

\section{Traditional Confucian Values}

Confucianism is woven into Chinese society. For hundreds of years, Confucianism has been actively taught (Chan, 2008). Regardless of an individual's religion, Confucianism defines the proper mode of conduct within Chinese society and within the family (Ralston et al., 2008). Chinese families use stories, sayings and special terms to instil Confucian ideals in children. The influence of Confucianism and its incorporation into the lives of so many for so long has built a tight matrix between the culture and the psychological character of the people (Yan and Sorenson, 2006). Research (Chan, 2008; Yan and Sorenson, 2006) has shown that, even in overseas Chinese family businesses, the most important family values are Confucian. In this context, the key Confucian factors are guanxi connections, family involvement, community guanxi, head of family, advice from elders, traditional wisdom, helping other Chinese, and trust in others. These Chinese family values and interpersonal patterns contribute to business development and success.

Traditional Confucian values will be explored to find the relationship between Chinese business success and these values, so:

H3. Entrepreneurial success of the Chinese is related to traditional Confucian values. 


\section{Difficulties and Hurdles}

The environment in the host communities impacts directly on newcomers' adaptation experience (Selvarajah, 2004). Culture shock emerges as a major hurdle for newcomers to a country in the relevant literature. Disorientation from being plunged into an unfamiliar setting is described as culture shock (McLaren 1998), and it has four significant contributing factors:

Language - Language is commonly perceived as a core difficulty in the relationship between an ethnic minority and the host group as it provides the means of communication and, more importantly, represents identity. The behaviour of language can also be explained by communal notions of social categorization, social identity, social comparison, psychological distinctiveness, and cognitive alternatives ( $\mathrm{Wu}$, 1995). For most migrants, the new language is at the heart of adjusting to a new country. Finocchiaro (1995) explained that language is much more than just a means of exchange between the two groups; they are also trying to understand, accept, assimilate, and reject each other's values. The significance of language in migrants' settlement is affirmed by sociologists, economists, linguists, and teachers and by migrants themselves (Burnett, 1998). In Australia, virtually every aspect of settlement hinges upon migrants having some English language ability.

Education - There is a maxim among Chinese parents that they put all their hope in the next generation. They do this by stressing the importance of higher education (Chu, 1995), so that the second generation are motivated to become high achievers. The general belief is that by studying hard and achieving academically, the younger generation will increase their opportunities of gaining wealth and respect, whereas without academic achievement they will be disregarded in society. Chinese see providing good education as one of the most important tasks of parents. They value education as preparation to move into a higher social order, and that sufficient education or training is a prerequisite for self-sufficiency and self-employment (Castles et al., 1991). Entrepreneurship is thought to be a path out of poverty that enables them to give their children higher human capital.

Adaptation - Adaptation has been a subject of sustained empirical and theoretical attention, and immigrant entrepreneurship has become part of this agenda. These entrepreneurial activities have been interpreted first in terms of immigrants' ethnicization, then adaptation, and most recently, transnationalism depending on the currently dominant discourse on their adaptation to their new environments (Light and Gold, 2000).

Previous work experience - According to the resource based perspectives, apart 
from education, human capital is derived from work experience. Research has shown a robust positive relationship between prior work experience in the same industry or line of business and venture success (Cooper et al., 1994). Researchers (e.g. Kitching et al., 2005; Ahlstrom et al., 2004) claim that if the work experience occurs within the same industry as new business venture, individual entrepreneurs gain opportunities to understand industry-specific market forces and identify potential market opportunities. Furthermore, work experience increases opportunities for individuals to obtain positions within various social networks that can be exploited for market information, access to capital, hiring employees, and developing supplier and customer relationships.

The fourth hypothesis of the study rests on the premise that Chinese immigrant entrepreneurs face significant barriers in their entrepreneurial endeavours that impede their progress. Chinese entrepreneurship literature (e.g. Ahlstrom et al., 2004) points out that the reduction of these barriers results in greater success for Chinese entrepreneurs (Kitching et al., 2005); so:

H4. Entrepreneurial success is related to overcoming the difficulties and hurdles experienced by the entrepreneurs.

\section{Overseas Expansionary Vision}

Stromback and Malhotra (1994) highlighted the entrepreneurial advantages of Asian (mainly Chinese) migrants because of their 'cultural baggage' and motivation. They emphasised the importance of these overseas networks of ethnic entrepreneurs in Australia. The links with relatives or friends in the country of origin are often used to provide a reliable supply, access to a market, advice about market prospects, and to secure credit. Similarly, Lever-Tracey et al. (1991) concluded that Chinese entrepreneurs are on the whole successful, innovative and export orientated entrepreneurs who have considerable overseas resources (including financial resources), business networks, and an 'anything-is-possible' attitude. These networks provide an advantage when establishing import/export activities because they provide personalized and trust-based networks that extend into the community, mainstream society and overseas. The growing expansion of quality Australian exports is an important factor in considering expanding businesses overseas.

In essence, the vision to exploit the advantages of overseas business connections is a form of innovation (Yeung 1999, Tsang 1998). The growing exportation of quality Australian goods to foreign countries becomes an important factor in considering expanding businesses overseas (Yeung and Chelliah, 2010). Overseas 
business connections are important in how Australian firms approach the creation of new businesses (Tsang 1998). Therefore, it is hypothesised that:

H5. Entrepreneurial success is related to the overseas expansionary vision of the entrepreneurs.

\section{METHODOLOGY}

For the purpose of data collection, the Australia-China Commerce and Economic Association, Inc., in Melbourne was contacted for their database of Chinese entrepreneurs. The Association agreed to mail out questionnaires to its members. Completed questionnaires were returned in a reply-paid envelope to the researchers. Responses were sought from different sectors (professionals, restaurants, real estate, trading companies, etc.), although this study does not intend to identify characteristics within industry sectors, but of the Chinese ethnic businesses generally.

A survey questionnaire was employed in this study because it was well suited to the descriptive and correlative nature of the study and it enabled a systematic collection of predominantly quantitative data (Kumar, 2005). The questionnaire collected quantitative data through 92 questions. The data was collected from January 2008 to April 2008. A total of 267 Chinese entrepreneurs agreed to participate in the research, but only 204 completed questionnaires were returned, and 4 questionnaires were discarded as incomplete, giving a return rate of 72 percent. The data collected were useful in measuring the identified variables and testing the specified hypotheses (Neuman, 2000) of the study, which contributed to the understanding of Chinese entrepreneurship. Table 1 below shows breakdown of respondents by generation (first or second) and industry grouping.

Table 1 Respondents by Generations \& Industry $(\mathrm{N}=200)$

\begin{tabular}{ccccccc}
\hline Industry & $\begin{array}{c}\text { Total } \\
\text { Number }\end{array}$ & $\mathbf{\%}$ & $\mathbf{1}^{\text {st }}$ Gen & $\mathbf{\%}$ & $\mathbf{2}^{\text {nd }}$ Gen & \% \\
\hline $\begin{array}{c}\text { Restaurant } \\
\text { Take-away }\end{array}$ & 54 & 27 & 43 & 32.6 & 11 & 16.2 \\
\hline Real estate & 16 & 8 & 10 & 7.6 & 6 & 8.8 \\
\hline 'Wet' retail such as grocery & 12 & 6 & 8 & 6.1 & 4 & 5.9 \\
\hline 'Dry' retail such as clothing & 36 & 18 & 16 & 12.1 & 20 & 29.4 \\
\hline Professional, such as doctor & 39 & 19.5 & 23 & 17.4 & 16 & 23.5 \\
\hline Other & 43 & 21.5 & 32 & 24.2 & 11 & 16.2 \\
\hline Total & 200 & 100 & 132 & 100 & 68 & 100 \\
\hline
\end{tabular}


In this study, the following assumptions have been made:

- The terms immigrant entrepreneurs and ethnic entrepreneurs, although not identical, are interchangeable (Collins, 1995).

- 'Entrepreneur' is defined as someone who owns his or her business. The person derives some income by engaging in business or economic activities as a self-employed person. The business may or may not be inherited through the family.

Criteria were used to identify the Chinese entrepreneurs for the sample, based on the following attributes:

- The entrepreneur either owned all of his or her business, or was the majority shareholder.

- The entrepreneur, who had initiated the business, was actively involved in managing it.

- The business of the Chinese entrepreneur was based in Melbourne.

- The business had been in operation for at least one year.

- The business employed less than 100 people.

The 92 questions were related to the research variables and the five hypotheses of the study. Each question consisted of multiple-choice answers. The subjects were to select the most appropriate answers based on their opinions derived from their personal experiences, thinking and knowledge. There was no right or wrong answer. The answers ranked from 'low importance' to 'high importance'. The use of multiple indicators allowed the authors to specify more precisely the desired responses. This did not place total reliance on a single response, but instead on the 'average' or 'typical' response to a set of related responses. The guiding premise was that multiple responses reflect the 'true' response more accurately than a single response. The questionnaire was structured into six sections.

Respondents were asked to rate the answers based of their personal views on engaging in their own business ventures on a 5-point scale, ranging from $1=$ little importance to $5=$ high importance. The questionnaire was used to collect information under five different groups:

- Importance of different factors in setting up one's own business (Q.1 - Q.8)

- Reasons for becoming an entrepreneur (Q.9 - Q.17)

- Views on different traditional Confucian values (Q.18-Q.23)

- Views on and importance of different difficulties and hurdles (Q.24-Q.68) 
- Importance of having 'overseas expansionary vision' in a business (Q.69 Q.79).

- The other questions related to entrepreneur's profile and demographic details (Q80. - Q92).

As indicated earlier, financial rewards are the best indicator of success in business, and is commonly used as a measure of success in entrepreneurship research (Rauch and Frese, 2000; Walker and Brown, 2004), It was used as the dependable variable in this research. SPSS software was used for carrying out various statistical tests. Structural Equation Modelling (SEM) was also used to establish the conceptual model for this study.

\section{RESULTS}

The scales developed previously for all the variables were subjected to multiple regression analysis to test the five hypotheses of the study. The use of the regression allowed the study to determine how well the five sets of independent variables were able to predict the dependent variable, business success. The results showed affirmative results for all the variables related to the dependent variable. Fourteen elements contributing to the success of businesses were identified, each showing high importance as contributing factors. Regression analysis was carried out on the results from both generations. The results from the analysis were used to test the five hypotheses. The results appear below:

H1. The background of the entrepreneurs is related to the success of their businesses - Supported

H2. Entrepreneurial success is related to the motivation of the entrepreneurs Supported

H3. Entrepreneurial success of the Chinese is related to traditional Confucian values - Supported

H4. Entrepreneurial success is related to the difficulties and hurdles experienced by the entrepreneurs - Supported

H5. Entrepreneurial success is related to the overseas expansionary vision of the entrepreneurs - Supported

The variables of each of the 14 factors (refer to Table 2 below) make a statistically significant contribution to the factors. This implies that all factors are important in the success of Chinese entrepreneurs. All five dimensions (background of 
the entrepreneurs, entrepreneurial motivations, traditional Confucian values, difficulties and hurdles and overseas expansionary vision), were found to be related to the business success of the entrepreneurs. In addition, the theoretical perspectives of the five dimensions of the study were found to be useful in explaining the success of the Chinese entrepreneurs. The results strongly support the characteristics of successful entrepreneurs presented by the extant literature. A new model (comprising all the component variables) explaining the success of Chinese entrepreneurs is put forward and tested in the next section.

It was important to determine if there was any influence of gender on the entrepreneurial behaviours of both generations. Multivariate tests on gender difference for 14 Constructs ( 2 Generations) were carried out. The respondents consisted of 110 males and 90 females. This proportion and the number of respondents add validity to the comparison of the genders between the two generations. However, there was no significant gender effect (Wilks Lambda $=.059, \mathrm{~F}(14,183)=.769, \mathrm{p}=.702)$. There was no significant interaction between gender and generation either (Wilks Lambda $=.932, \mathrm{~F}(14,183)=.956, \mathrm{p}=.500)$.

Regression analysis is the appropriate method when a research problem involves a single metric dependent variable presumed to be related to two or more metric independent variables (Creswell, 2003). Here, the outcome variable is financial rewards, which equals business success. The other 13 scales become independent variables. The objective of this analysis is to predict the changes in the dependent variable (financial rewards) in response to changes in the independent variables. The model in Table 2 explains 64.8 percent of the variation in the dependent variable, financial rewards, when fitted using structural equation modelling.

Table 2 Model Summary of Regression Square

\begin{tabular}{lcccc}
\hline \multicolumn{5}{c}{ Model Summary } \\
\hline Model & $\mathrm{R}$ & R Square & Adjusted R Square & Std. Error of the Estimate \\
\hline 1 & $.805^{\mathrm{a}}$ & .648 & .624 & .50060 \\
\hline a. Predictors: (constant), guanxi, Personal Hurdles, Financial Rewards, Overseas Expansionary \\
Vision, Prior Experience, Bureaucracy \& & Regulation, Potential Seeking, Self-satisfaction, \\
External Hurdles, Adaptation, Business & Set-up, Adaptive Opportunism, Confucian Piety, \\
Business Management & & \\
\hline
\end{tabular}

In the following regression equation only three variables (business management, adaptive opportunism and overseas expansionary vision - each with significant value 
less than < 0.05) have a direct relationship with the outcome - financial rewards. Although the other variables have a significant correlation with financial rewards, they do not have a direct relationship with it, only an indirect relationship by way of the three strategy variables. In Table 3, the percentage variations for 11 factors being investigated is highlighted using squared multiple correlations. They indicate the contributions of each factor towards the model.

Table 3 Squared multiple correlations of 11 factors

\begin{tabular}{ccl}
\hline Factors & Estimate & \multicolumn{1}{c}{ Explanation } \\
\hline Guanxi connections & .365 & $\begin{array}{l}\text { The model explains } 37 \text { percent of variation in Guanxi } \\
\text { Connections }\end{array}$ \\
\hline Prior Experience & .367 & $\begin{array}{l}\text { The model explains } 37 \text { percent of variation in Prior } \\
\text { Experience }\end{array}$ \\
\hline Adaptation & .366 & The model explains 37 percent of variation in Adaptation \\
\hline External Hurdles & .644 & $\begin{array}{l}\text { The model explains } 64 \text { percent of variation in External } \\
\text { Hurdles }\end{array}$ \\
\hline Personal Hurdles & .445 & $\begin{array}{l}\text { The model explains } 45 \text { percent of variation in Personal } \\
\text { Hurdles }\end{array}$ \\
\hline Business Set-up & .582 & $\begin{array}{l}\text { The model explains } 58 \text { percent of variation in Business } \\
\text { Set-up }\end{array}$ \\
\hline Bureaucracy $\&$ & .505 & $\begin{array}{l}\text { The model explains } 51 \text { percent of variation in Bureaucracy } \\
\& \text { Regulation }\end{array}$ \\
\hline Regulation & .640 & $\begin{array}{l}\text { The model explains } 64 \text { percent of variation in Business } \\
\text { Management }\end{array}$ \\
\hline Fusiness Management & .488 & $\begin{array}{l}\text { The model explains } 49 \text { percent of variation in Overseas } \\
\text { Expansionary Vision }\end{array}$ \\
\hline Overseas Expansionary \\
Vision
\end{tabular}

$($ Chi-Square $=58.5, \mathrm{df}=35, \mathrm{p}=.008)$.

The most important factors associated with financial rewards for the ethnic Chinese entrepreneurs are ranked from highest to lowest:

- Confucian piety, with a total standardized effect size of 0.473

- Business management, with a total standardized effect size of 0.464

- Adaptation, with a total standardized effect size of 0.363 
- External hurdles, with a total standardized effect size of 0.332

- Overseas expansionary vision, with a total standardized effect size of 0.331 .

Overall, the following conclusions can be drawn for the ethnic Chinese entrepreneurs (combined first and second generation entrepreneurs).

- The highest ranked is Confucian piety, which is unique to the Chinese entrepreneurs. This implies that traditional Confucian values are the most important in the success of their businesses.

- The other three factors, business management, adaptation, and external hurdles, are important to all entrepreneurs and are not unique to Chinese entrepreneurs. These factors are important for both Chinese and non-Chinese entrepreneurs in running their businesses.

- Overseas expansionary vision is a major factor in determining the success of entrepreneurship, especially in those entrepreneurs who have the vision and innovation to expand their existing businesses or initiate new overseas businesses.

The factors above are depicted in Figure 1. Straight arrows represent the impact of independent variables on the dependent variables, and curved arrows depict the correlation among variables. All factors within the model are linked. The model is a dynamic system, influenced by all the factors. The importance of each individual factor can be correlated and measured against the others. Therefore, the model can be tested and proven if it is a 'tight and good-fit' model. The model will also be compared between the two generations to determine variance. Financial reward is used as the outcome of the model. The elements are the factors of successful entrepreneurs. 


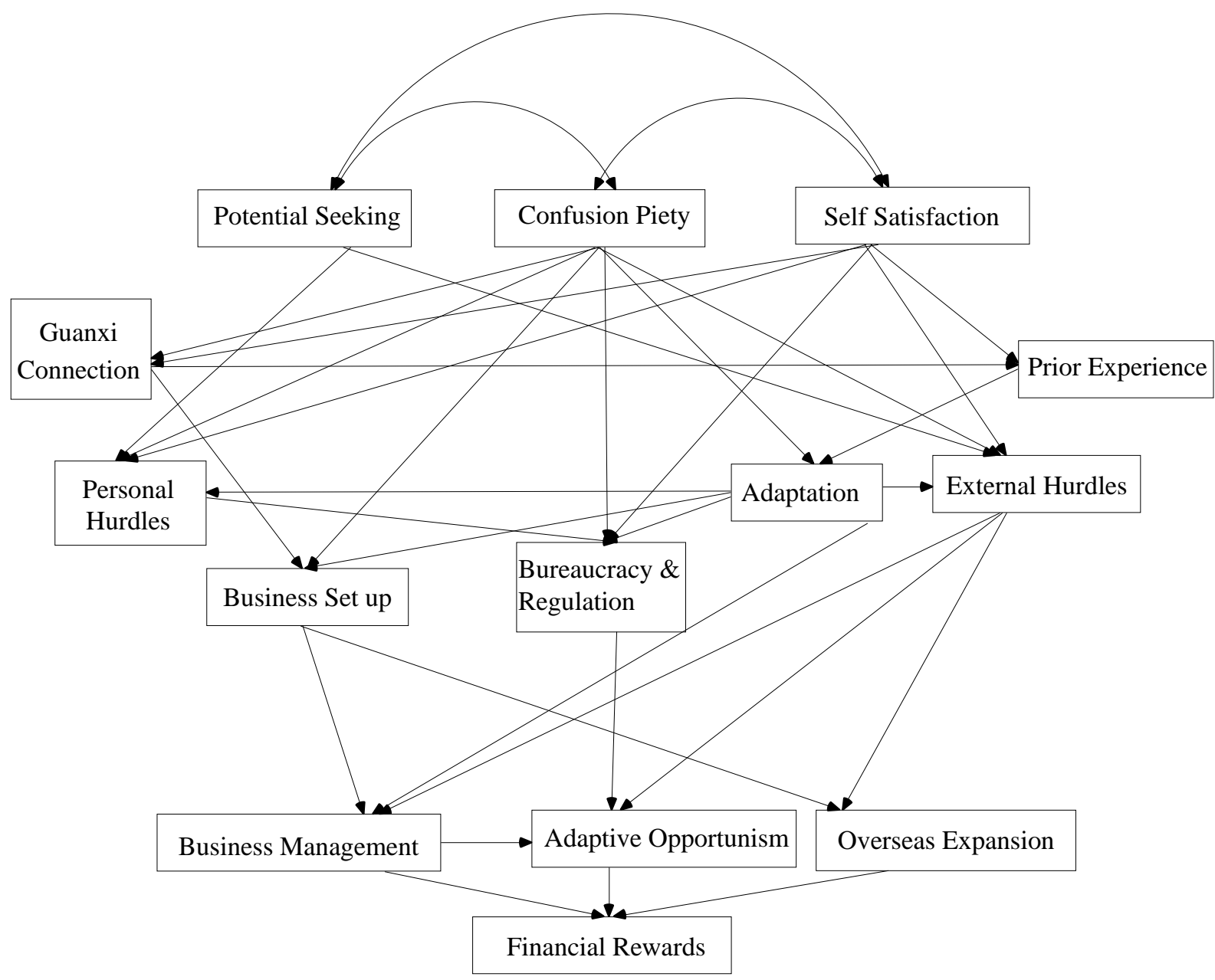

Figure 1 Migrant Ethnic Chinese Entrepreneurship Success Model

\section{COMPARISON OF THE TWO GENERATIONS}

In this section, the ethnic Chinese entrepreneurs sample is split into first generation $(\mathrm{N}=132)$ and second generation $(\mathrm{N}=68)$. Both groups are subjected to regression analysis separately. The aim is to find out if the profiles of the two generations vary. Also, separate results can give further details about each individual group, so that better insight about the two generations of Chinese entrepreneurs can be obtained.

Multivariate test results show that there were differences between the generations in terms of their entrepreneurial profiles (df1=105, and df2 -60697, $\mathrm{p}=0.004$,). Therefore, the study of each generation was necessary and separate regression analysis was carried out. The results are summarized as in Table 4. 
- Out of a total 32 relationships, 23 relationships (71.9 percent) have the same 'significance' in both generations, and these relationships are important $(\mathrm{p}<0.05)$ in both generations.

- The remaining 9 relationships (19.1 percent) shows opposite 'significance' between the first and second generation, as follows:

Table 4 Summary of Regression Weights for First and Second Generations

\begin{tabular}{|c|c|c|c|}
\hline \multicolumn{2}{|c|}{ Relationship between } & \multirow{2}{*}{$\frac{\mathbf{1}^{\text {st }} \text { Generation }}{\mathrm{S}}$} & \multirow{2}{*}{$\begin{array}{c}2^{\text {nd }} \text { Generation } \\
\text { NS }\end{array}$} \\
\hline Confucian Piety & Guanxi Connections & & \\
\hline Prior Experience & Adaptation & NS & $\mathrm{S}$ \\
\hline Confucian Piety & Personal Hurdles & $S$ & NS \\
\hline Self-satisfaction & External Hurdles & $\mathrm{S}$ & NS \\
\hline Potential Seeking & External Hurdles & $\mathrm{S}$ & NS \\
\hline Self-satisfaction & Personal Hurdles & NS & $S$ \\
\hline Confucian Piety & Business Set-up & NS & $\mathrm{S}$ \\
\hline Personal Hurdles & $\begin{array}{c}\text { Bureaucracy \& Regulation } \\
\text { \& Regulation }\end{array}$ & S & NS \\
\hline Adaptive Opportunism & Financial Rewards & $\mathrm{S}$ & NS \\
\hline
\end{tabular}

The results of the independent sample T-test and the Mann-Whitney U Test clearly indicate that there are differences in the relationships between the two generations. Firstly, though the results support the argument that traditional Confucian values play an important role in Chinese entrepreneurship, there is a reduction in the importance of traditional Confucian values from the first to the second generation. The embedding of 'Chinese-ness' is not as important to the second generation because it has been exposed to Australian lifestyle and culture. Secondly, the other motivational factors, 'potential seeking' and 'self-satisfaction' also show a difference between the two generations, due to the differences in views on dealing with the 'external' and 'personal' hurdles. The most important factors associated with financial rewards for the first generation Chinese are ranked as follows:

- Confucian piety, with a total standardized effect size of 0.505

- Business management, with a total standardized effect size of 0.410

- Overseas expansionary vision, with a total standardized effect size of 0.364

- Adaptation, with a total standardized effect size of 0.360

- External hurdles, with a total standardized effect size of 0.357

- Business set-up, with a total standardized effect size of 0.296. 
These factors are similar to those of the whole pool $(\mathrm{N}=200)$ in the previous section. However, there are two differences. Firstly, the factor overseas expansionary vision has moved to the third rank instead of the fifth in the earlier section. This indicates the higher importance of the factor due to close links and better overseas know-how in the first generation. Secondly, business set-up has been added. This indicates that the first generation places higher importance in establishing the businesses when they newly arrive in Australia.

The most important factors associated with financial rewards for the second generation Chinese are ranked as follows:

- Business management, with a total standardized effect size of 0.605

- Confucian piety, with a total standardized effect size of 0.403

- Adaptation, with a total standardized effect size of 0.340

- Business set-up, with a total standardized effect size of 0.313

- External hurdles, with a total standardized effect size of 0.287

- Overseas expansionary vision, with a total standardized effect size of 0.259.

Although the factors in the second generation are the same as the first generation, the ranking varies. Business management replaces Confucian piety as the most important factor, suggesting that the second generation are more concerned with business administration and management in the Australian context than on the importance of Confucian values.

The importance of overseas expansionary vision ranks number 6. The explanation can be that the second generation has become more 'Australianized' and localized. This can also be interpreted as having greater opportunity to penetrate locally, and also that contact with the parent's home country becomes less personal or meaningful. This is referred to by academics (e.g. Tung, 2008) as 'crossvergence' where the Chinese internalize some aspects of Western individualism into their Confucian-based value system.

The second generation entrepreneurs display a greater reliance on 'guanxi connections' during the journey of entrepreneurship than the first generation entrepreneurs. The difference is due to their higher need for financial back-up, entrepreneurial foundation and business networking. Second generation Chinese entrepreneurs rely on guanxi connections to develop personal and business networks rather than use external business support to help them in their operation. The use of such business support in the areas of legal and accounting services, feasibility studies, development of business plans, and production, marketing and management services 
benefit Chinese entrepreneurs in the start-up phases of their businesses, and also boost their performance in terms of turnover and growth.

Prior experience measures the importance of previous exposure to entrepreneurship. The study reported that 97 percent of second generation entrepreneurs chose role models as an important or very important factor in setting up businesses (compared to 78.8 percent in the first generation). This shows that the entrepreneurs placed emphasis on learning from the experiences of their role models. The second generation relies on learning business acumen from others, like family.

Lastly, the second generation places more importance on self-satisfaction. The first generation entrepreneurs spend more time in feeding their families while the second generation are more financially independent, so they focus on satisfying their own dreams and goals.

\section{CONCLUSION}

This study identifies the foundation factors that enable Chinese entrepreneurs to set up and operate business ventures. Fourteen independent variables in relation to the five hypotheses have been identified. The results show statistically significant support for all the hypotheses. Therefore, these variables can be used to construct profiles of Chinese entrepreneurs in both generations.

The findings confirm that Chinese entrepreneurs in both generations possess relevant business knowledge, skills, personal attributes and capabilities that are useful to them when they are establishing their businesses. Two major factors were identified: guanxi connections and prior experience. However, the second generation place greater emphasis on being a role model for the family and community than the first generation. Figure 2 shows the congruence and divergence in this respect between the two generations. 
Role Model (less important in $1^{\text {st }}$ generation)

Advice from friends

(similar in both generations)

Better Education

( similar in both generations)

Personal expertise (less important in

$I^{\text {st }}$ generation)

Independent decision making

(similar in both generations)

Prior Entrepreneurial experience

(similar in both generations)

Passion to succeed

(similar in both generations)

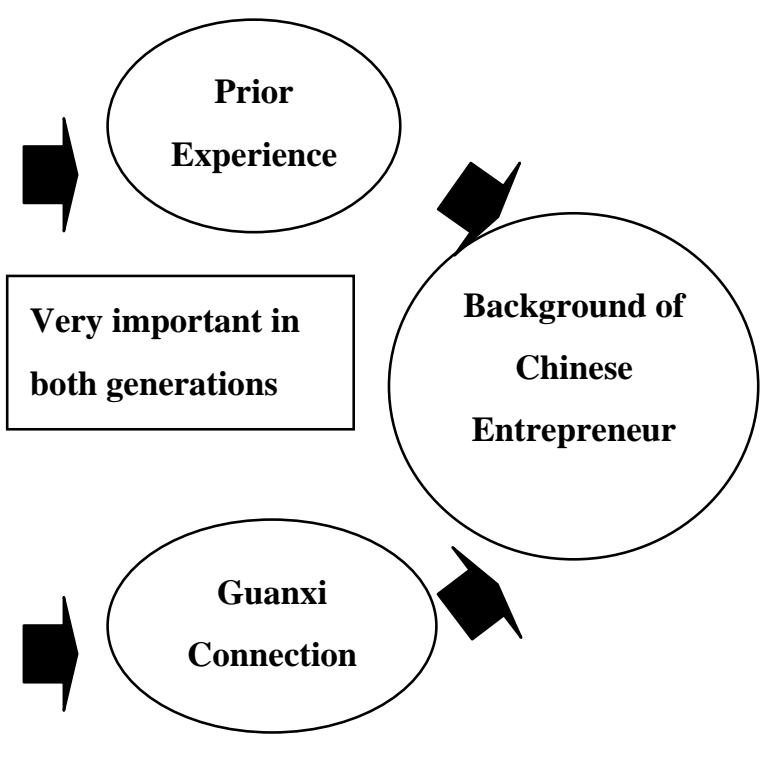

$$
\begin{aligned}
& \text { Very important in } \\
& \text { both generations }
\end{aligned}
$$

Figure 2 Key Characteristics of Background of Chinese Entrepreneurs

The study found that self-satisfaction and potential seeking were major motivational factors for these entrepreneurs. The study found that both generations valued traditional Confucianism: the importance of the head of family, helping other Chinese, seeking support from the community, trust and family involvement and 'guanxi' (see Figure 3 below). 
Migration (less important in $2^{\text {nd }}$ gen.)

Dissatisfaction with previous job (less important in $2^{\text {nd }}$ gen.)

Envy of other (similar)

Profit maximization (similar)

Inheritance of family business (same)

Freedom (similar in both generations)

Desire (less important in $2^{\text {nd }}$

generation)

Potential to make more money

(similar in both generations)

Strong belief in capability ( similar in

both generations)

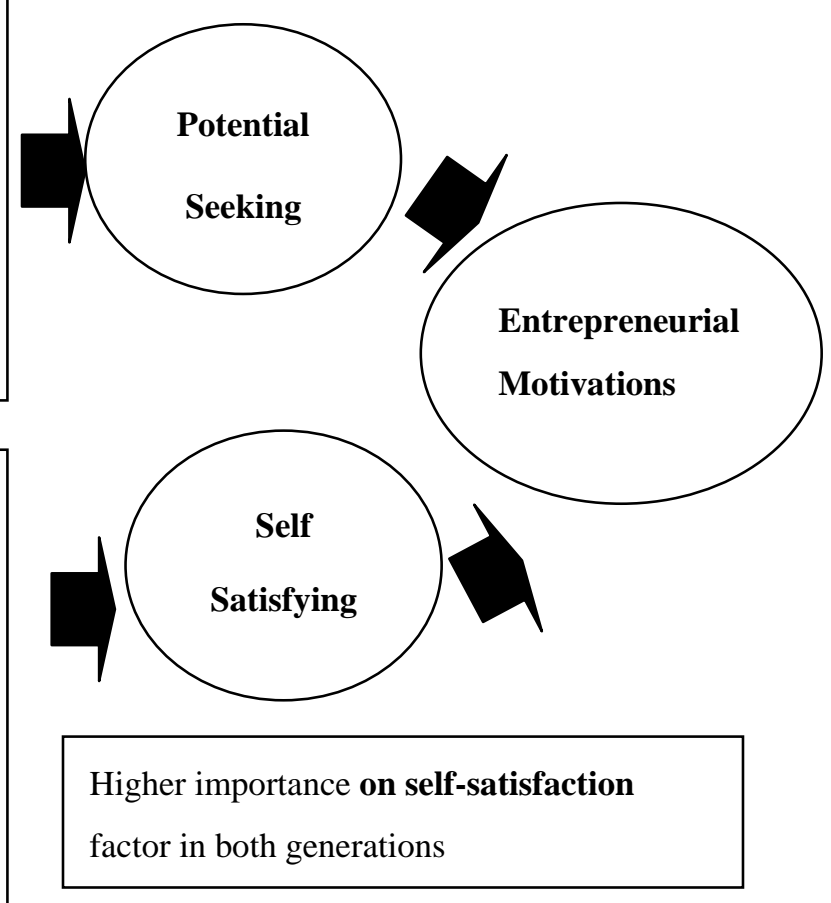

Figure 3 Key Characteristics of Entrepreneurial Motivation

The study also reveals that both generations share similar views and attitudes towards hurdles and difficulties encountered during the journey of entrepreneurship. In this respect good management skills and organisation skills are seen as necessary for overcoming difficulties and hurdles. However, for the second generation, values are clearly more individualistic, less collectivistic and less committed to Confucian philosophy than the first generation. This is referred to as 'crossvergence,' where the second generation Chinese internalize some aspects of Western individualism into their Confucian-based value system (see Figure 4 below). 
Guanxi connections (most important in both

generations)

Family involvement

(similar in both generations)

Community Guanxi

(similar in both generations)

Head of family

(similar in both generations)

Elderly advice (less important in the $2^{\text {nd }}$

generation)

Traditional wisdom

(similar in both generations)

Helping other Chinese (less important in $2^{\text {nd }}$ generation)

Racial discrimination

(similar in both generations)

Trust in others (less important in $2^{\text {nd }}$

generation)

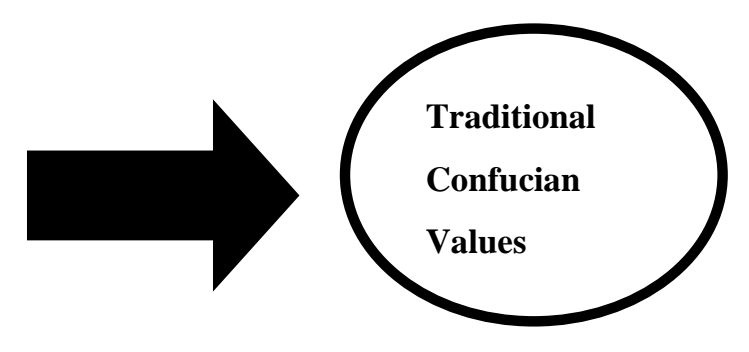

Figure 4 Key Characteristics of Traditional Confucian Values Important to Chinese Entrepreneurship in Australia

This study also identified the overseas expansionary vision factors that enable the Chinese entrepreneurs to see beyond their existing business ventures and prepare for expansion. While overseas expansion was of higher importance to the first generation, the second generation prefer to expand their businesses locally (see Figure 5 below). 
Anything-is-possible

(similar in both generations)

Borderless trading (more

important in $2^{\text {nd }}$ generation)

Attractive overseas market

(similar in both generations)

More travel (more important in

$1^{\text {st }}$ generation)

Overseas connection (similar

in both generations)

Cheaper supplies

(similar in both generations)

Potential to make more money

(more important in $1^{\text {st }}$

generation)

More satisfaction

(similar in both generations)
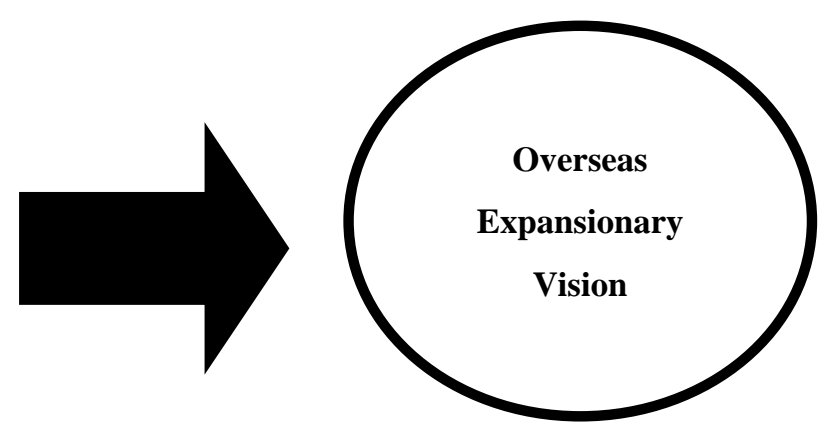

Figure 5 Key Characteristics of Overseas Expansionary Vision

In relation to difficulties and hurdles, the questions supporting the variables show 'similar' or 'no difference' in the data of the two generations. This implies that the views and attitudes towards difficulties and hurdles encountered during the journey of entrepreneurship are the same for both generations. All attributes remain major contributors to the difficulties and hurdles, and the results show the high importance of all factors (see Figure 6 below). 


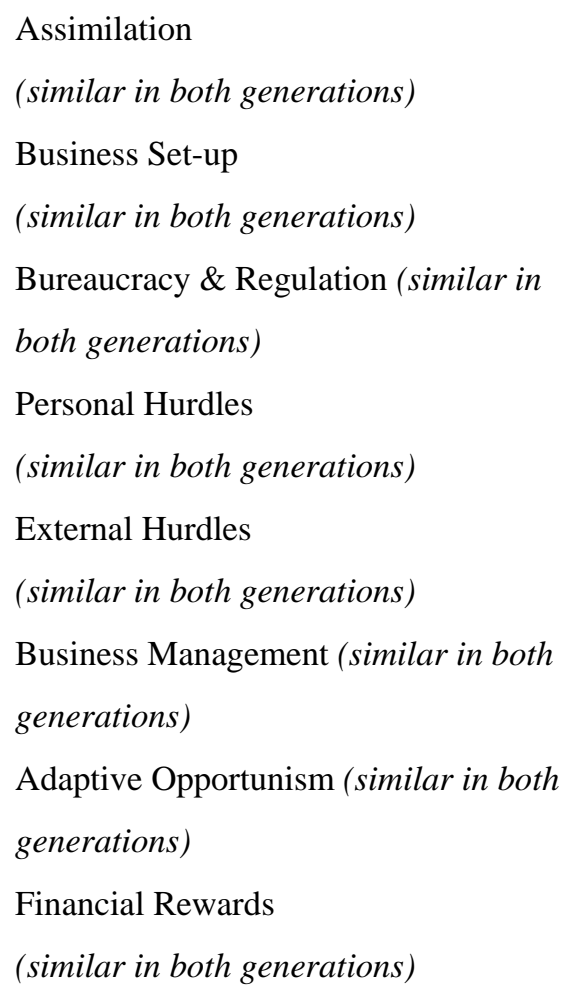

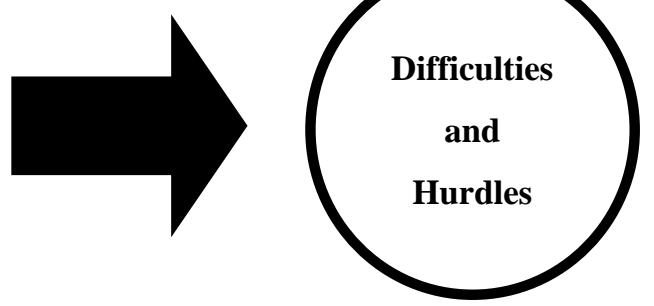

Figure 6 Key Characteristics of Difficulties and Hurdles Impacting Chinese

\section{Entrepreneurship}

Overall, the study provides an understanding of the performance of Chinese entrepreneurs in Melbourne. The future economic growth of Australia will surely be tied to the growth of migration from Asia, especially China, Japan and India. This study supports the theory that multiculturalism is good for business. These migrants and their descendants introduce multilingualism, cultural sensitivity, knowledge, training and qualifications earned overseas. Many ethnic entrepreneurs use these attributes and other unique ethnic resources to develop their enterprises.

Regardless of location, the increased attention to economic contributions, in particular the growing of successful businesses, is reflected in the accelerated pace of public and private sector policy initiatives at all levels. Various studies have identified that small enterprises are the main drivers of economic growth, so the findings of this research should prove useful for policy makers and stakeholders. It can also serve as a 
foundation for a comprehensive Australia-wide study of ethnic entrepreneurship.

\section{LIMITATIONS/FUTURE RESEARCH}

This study is restricted to the database obtained from the Chinese Chamber of Commerce in Melbourne, a non-profit agency for small businesses. The database obtained cannot be considered to be an exhaustive list of all small Chinese businesses nor representative of all suburbs in Melbourne. Nevertheless, 200 usable completed questionnaires were collected out of 267 distributed, a 74.9 percent response rate. According to Hart (1987), response rates in business surveys vary from 17 percent to 60 percent, with an average of 36 percent, so the response rate of 74.9 percent was more than acceptable. Further, the findings in the study were limited by the extent to which the respondents were honest, careful and without bias in responding to the survey instrument. Finally, the type of business in itself may be a limitation. These limitations will become the platform for future studies. These future studies could focus on other regions of Australia or other minority ethnic entrepreneurs.

\section{REFERENCES}

Ahlstrom, D., Chan, E. M., \& Bruton, G. D. (2004). Facing constraints to growth? Overseas Chinese entrepreneurs and traditional business practices in East Asia. Asia Pacific Journal of Management, 21(1), 263-285.

Amit, R., \& Muller, E. (1995). 'Push' and 'pull' entrepreneurship based on motivation. Journal of Small Business and Entrepreneurship, 12(4), 64-71.

Bandura, A. (1977). Social learning theory. New Jersey: Prentice-Hall.

Brush, C. G., Carter, N., Gatewood, E., Greene, P. \& Hart, M. (2006). Growth-oriented women entrepreneurs and their businesses: a global research perspective. Cheltenham: Edward Elgar Publishing.

Burnett, L. (1998). Issues in immigrant settlement in Australia, National Centre for English Language Teaching and Research. Sydney: Macquarie University.

Castles, S., Collins, J., Gibso, K., Tait, D., \& Alcorso, C. (1991). The global milkbar and local sweatshop: ethnic small business and the economic restructuring of Sydney. The Office of Multicultural Affairs, Centre for Multicultural Studies: University of Wollongong, Australia.

Chan, G. K. Y. (2008). The relevance and value of Confucianism in contemporary business ethics. Journal of Business Ethics, 77(3), 347-360. 
Chu, C. (1995). The Asian mind game: unlocking the hidden agenda of the Asian business culture - a Westerner's survival manual. Crows Nest: Stealth Productions.

Collins, J. (1995). Asian migration to Australia. In R. Cohen (Eds.), The Cambridge survey of world migration (pp. 376-379). Cambridge: Cambridge University Press.

Cooper, A., Gimeno-Gascon, F. \& Woo, C. (1994). Initial human and financial capital as predictors of new venture performance. Journal of Business Venturing, 9(5), 331-395.

Creswell, J. W. (2003). Research design: qualitative, quantitative and mixed approaches ( $2^{\text {nd }} E d$.). California: Sage Publications.

Finocchiaro, C. (1995). Intergenerational language maintenance of minority groups in Australia in the 1990s: an Italian case study. Journal of Intercultural Studies, 16(2), 41-54.

Kempster, S. \& Cope, J. (2010). Learning to lead in the entrepreneurial context. International Journal of Entrepreneurial Behaviour \& Research, 16(1), 5-34.

Kitching, B. M., Mishra, R. \& Shu, X. (2005). Female entrepreneurs in transitional economies: a comparative study of women in the business workplace in India and China. Discussion Paper 16: ABERU.

Kumar, R. (2005). Research methodology, a step-by-step guide for beginners. London: Sage Publications.

Lerner, M., Brush, C., \& Hisrich, R. (1997). Israeli women entrepreneurs: an examination of factors affecting performance. Journal of Business Venturing, 12(4), 315-399.

Lever-Tracy, C., Ip, D., Kitay, Phillips, J., \& Trace, N. (1991). Asian entrepreneurs in Australia. Office of Multicultural Affairs: Australian Government Publishing Service.

Light, I., \& Gold, S. J. (2000). Ethnic economies. San Diego: Academic Press.

McLaren, M. C. (1998). Interpreting cultural difference: the challenge of intercultural communication. Norfolk: Peter Francis Publishers.

Neuman, W. L. (2000). Social research methods: qualitative and quantitative approaches. Boston: Allyn and Bacon.

Ralston, D. A., Holt, D. H., Terpstra, R. H., \& Yu, K. C. (2008). The impact of national culture and economic ideology on managerial work values: a study of the United States, Russia, Japan, and China. Journal of International Business Studies, 39(1), 8-26. 
Rauch, A., \& Frese, M. (2000). Psychological approaches to entrepreneurial success: a general model and an overview of findings. In C. L. Cooper, \& I. T. Robertson (Eds.), International review of industrial and organizational psychology (pp. 101-142). Chichester: Wiley.

Rusinovic, K. (2008). Moving between markets? Immigrant Entrepreneurs in different markets. International Journal of Entrepreneurial Behaviour \& Research, 14(6), 444-454.

Selvarajah, C. (2004). Expatriation experiences of Chinese immigrants in New Zealand: factors contributing to adjustment of older immigrants. Management Research News, 27(9), 26-45.

Stromback, T., \& Malhotra, R. (1994). Socioeconomic linkages of South Asian immigrants with their country of origin. Canberra: BIPR and Australian Government Publishing Service.

Tsang, W. K. (1998). Can guanxi be a source of sustained competitive advantage for doing business in China? The Academy of Management Executive, 12(2), 64-73.

Tung, R. L. (2008). The cross-cultural research imperative: the need to balance cross-national and intra-national diversity. Journal of International Business Studies. 39(6), 41-46.

Walker, E., \& Brown, A. (2004). What success factors are important to small business owners? International Small Business Journal, 22(6), 577-594.

Wu, S. M. (1995). Maintenance of the Chinese language in Australia. Australian Review of Applied Linguistics, 18(2), 105-136.

Yan, J., \& Sorenson, R. (2006). The effect of Confucian values on succession in family business. Family Business Review, 19(3), 235-250.

Yang, M. M. (2002). The resilience of guanxi and its new deployments: a critique of some new guanxi scholarship. China Quarterly, 170(June), 459-476.

Yeung, H. (1999). The internationalization of ethnic Chinese business firms from Southeast Asia: Strategies, processes and competitive advantage. International Journal of Urban and Regional Research, 23(1), 88-102.

Yeung, S. T., \& Chelliah, J. (2010), International Strategies of Australian Firms. Journal of International Management Studies, 5(2), 131-141. 
